\title{
Desenvolvendo o Raciocínio Lógico no Ensino Médio: uma proposta utilizando a ferramenta Scratch
}

\author{
Fernanda P. Mota, Nathan F. A. Ribeiro, Leonardo Emmendorfer, Paulo Butzen, \\ Karina S. Machado, Diana F. Adamatti
}

Centro de Ciências Computacionais - Universidade Federal do Rio Grande (FURG) Av. Itália km 8-Campus Carreiros - 96.201-900 - Rio Grande- RS - Brasil

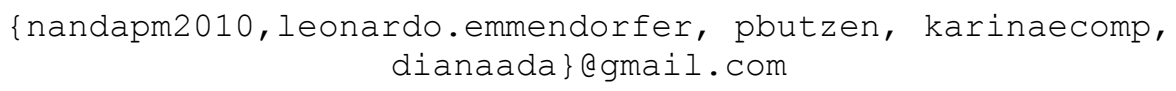

\begin{abstract}
Resumo. Nos últimos anos houveram melhorias institucionais nas instalações físicas e de recursos materiais e humanos, tornando as escolas e organizações educacionais mais adequadas para o desempenho dos seus papéis. No Brasil, as políticas de implantação de laboratórios de informática nas escolas públicas têm sido norteadas na direção da mudança pedagógica. Porém, é de conhecimento geral que a computação vai além do uso do computador para a realização de atividades rotineiras, podendo ser utilizado no desenvolvimento de novos programas com diferentes funcionalidades, uma atividade que envolve conhecimentos de lógica de programação. Essa integração da lógica de programação no ensino básico e profissional pode auxiliar na resolução de diferentes problemas de forma estruturada e racional. Sendo assim, este trabalho propõem a aplicação de um curso de lógica de programação por meio da ferramenta Scratch para adolescentes do ensino médio em uma escola pública.
\end{abstract}

\section{Introdução}

A tarefa de melhorar nosso sistema educacional, o qual é dinâmico e complexo, exige a atuação dos docentes e do governo em múltiplas dimensões e decisões fundamentadas e criativas. Estas ações demonstraram melhorias institucionais nas instalações físicas e em recursos materiais e humanos, tornando, assim, as escolas e organizações educacionais mais adequadas para o desempenho dos papéis que lhes cabem. Além disso, houve melhorias nas condições de atendimento às novas gerações, demonstradas na adequação dos currículos e dos recursos para os jovens provocando ganhos substanciais na aprendizagem dos estudantes [Valente et al., 1998]

No Brasil, as políticas de implantação de laboratórios de informática nas escolas públicas têm sido norteadas na direção da mudança pedagógica. Embora os resultados dos projetos governamentais sejam modestos, esses têm sido coerentes e sistematicamente têm enfatizado a mudança na escola. Isso vem ocorrendo desde 1982, quando essas políticas começaram a ser delineadas [Valente, 1998].

É de conhecimento geral que a computação vai além do uso do computador para a realização de atividades rotineiras como acesso a internet e elaboração de textos e trabalhos. O computador pode ser utilizado no desenvolvimento de novos programas ou jogos com diferentes funcionalidades, uma atividade que envolve conhecimentos de lógica de programação que podem ser aplicados em várias áreas, não se limitando a informática. A integração da lógica de programação no ensino básico e profissional pode auxiliar na resolução de problemas de forma estruturada e racional. A inserção desse novo conhecimento pode tornar mais visível aos alunos o papel das ciências 
exatas no desenvolvimento do país.

Neste sentido, este trabalho propõem a aplicação de um curso de lógica de programação por meio da ferramenta Scratch para adolescentes do ensino médio em uma escola pública. Deste modo, as seções a seguir, as quais demonstram mais detalhes desta proposta estão organizadas da seguinte maneira: seção 2 descreve resumidamente os aspectos conceituais do ensino de computação; a seção 3 demonstra a ferramenta utilizada no curso; a seção 4 relata a proposta de trabalho e resultados parciais. Por fim, na seção 5 têm-se considerações finais e os trabalhos futuros.

\section{O ensino de Computação}

Atualmente, o emprego dos computadores na Educação é muito mais diversificado, interessante e desafiador, do que simplesmente a de transmitir informação ao aprendiz. O computador pode ser também utilizado para enriquecer ambientes de aprendizagem e auxiliar o aprendiz no processo de construção do seu conhecimento. O Programa Nacional de Informática na Educação ProInfo é um grande esforço desenvolvido pelo MEC para introduzir as tecnologias de informática e telecomuniçções - telemática na escola pública.

O computador não é mais utilizado apenas para ensinar conteúdos de ciência da computação ou "alfabetização em Informática", mas também para que o aluno adquira conceitos computacionais, como princípios de funcionamento do computador, noções de programação e implicações do computador na sociedade. Essa abordagem foi bastante divulgada nos Estados Unidos como computer literacy e foi à solução que muitas escolas, no Brasil encontraram para inserir o computador no processo ensinoaprendizagem. Para tanto, o currículo foi incrementado com a disciplina "Introdução à Informática", cujo objetivo é ensinar computação que permitiu ao aluno conhecer o computador. Porém, do ponto de vista educacional, não altera o modo como os conteúdos das outras disciplinas são ministrados [Valente, 1998].

Quando o aluno usa o computador para construir o seu conhecimento, o computador passa a ser uma máquina para ser ensinada, propiciando condições para o aluno descrever a resolução de problemas, usando linguagens de programação, refletir sobre os resultados obtidos e depurar suas ideias por intermédio da busca de novos conteúdos e novas estratégias. Nesse caso, os softwares utilizados podem ser os softwares abertos de uso geral, como as linguagens de programação, sistemas de autoria de multimídia, ou aplicativos como processadores de texto, software para criação e manutenção de banco de dados [Baranauskas et. al., 1998].

Desta forma, o uso do computador na criação de ambientes de aprendizagem que enfatizam a construção do conhecimento apresenta enormes desafios. Primeiro, implica em entender o computador como uma nova maneira de representar o conhecimento, provocando um redimensionamento dos conceitos já conhecidos e possibilitando a busca e compreensão de novas ideias e valores. Usá-lo com essa finalidade requer a análise cuidadosa do que significa ensinar e aprender, bem como demanda rever o papel do professor nesse contexto. Segundo, a formação desse professor envolve muito mais do que provê-lo com conhecimento sobre computadores.

A implantação da computação como um auxiliar do processo de construção do conhecimento, implica em mudanças na escola que vão além da formação do professor. É necessário que todos os segmentos da escola - alunos, professores, administradores e comunidade de pais - estejam preparados e suportem as mudanças educacionais necessárias para a formação de um novo profissional. Nesse sentido, a Informática é um dos elementos que deverá fazer parte da mudança, porém essa mudança é muito mais 
profunda do que simplesmente montar laboratórios de computadores na escola e formar professores para a utilização dos mesmos.

Segundo Sousa (2011), um software educacional é um programa de computador que visa atender necessidades e possuem objetivos pedagógicos. Contudo, todo software pode ser considerado educacional, desde que sua utilização esteja inserida num contexto e em uma situação de ensino-aprendizagem, favorecendo seu desenvolvimento e propiciando meios que enriquecem a prática docente.

\section{Ferramenta Scratch}

Scratch foi desenvolvido por uma parceria entre MIT e UCLA, nos Estados Unidos. Este não é o primeiro ambiente e linguagem de programação destinados a programadores iniciantes. De fato, há uma rica história de diferentes ferramentas com esse propósito [Maloney et. al.,2008]. O Scratch se baseia nas idéias de Logo [McCray et al.,2003], mas substitui código digitado por uma abordagem de "arrastar-e-soltar" que é inspirado pelo LogoBlocks [Wolz et.al.,2008] e pelo Etoys ${ }^{1}$.A ferramenta enfatiza a manipulação de mídias e apóia as atividades de programação que despertam interesse em juvens, tais como a criação de histórias animadas, jogos e apresentações interativas.

Scratch foi originalmente projetado como um ambiente de programação rico de mídia para introduzir e motivar programação em escolas [Resnick et. al., 1998], [Resnick et. al., 2003]. Os programas são construídos por meio da montagem de pilhas de blocos de comandos coloridos que eliminam problemas de sintaxe, e incentivam a exploração do ambiente. A Figura 1 mostra a Interface de desenvolvimento da ferramenta Scratch.

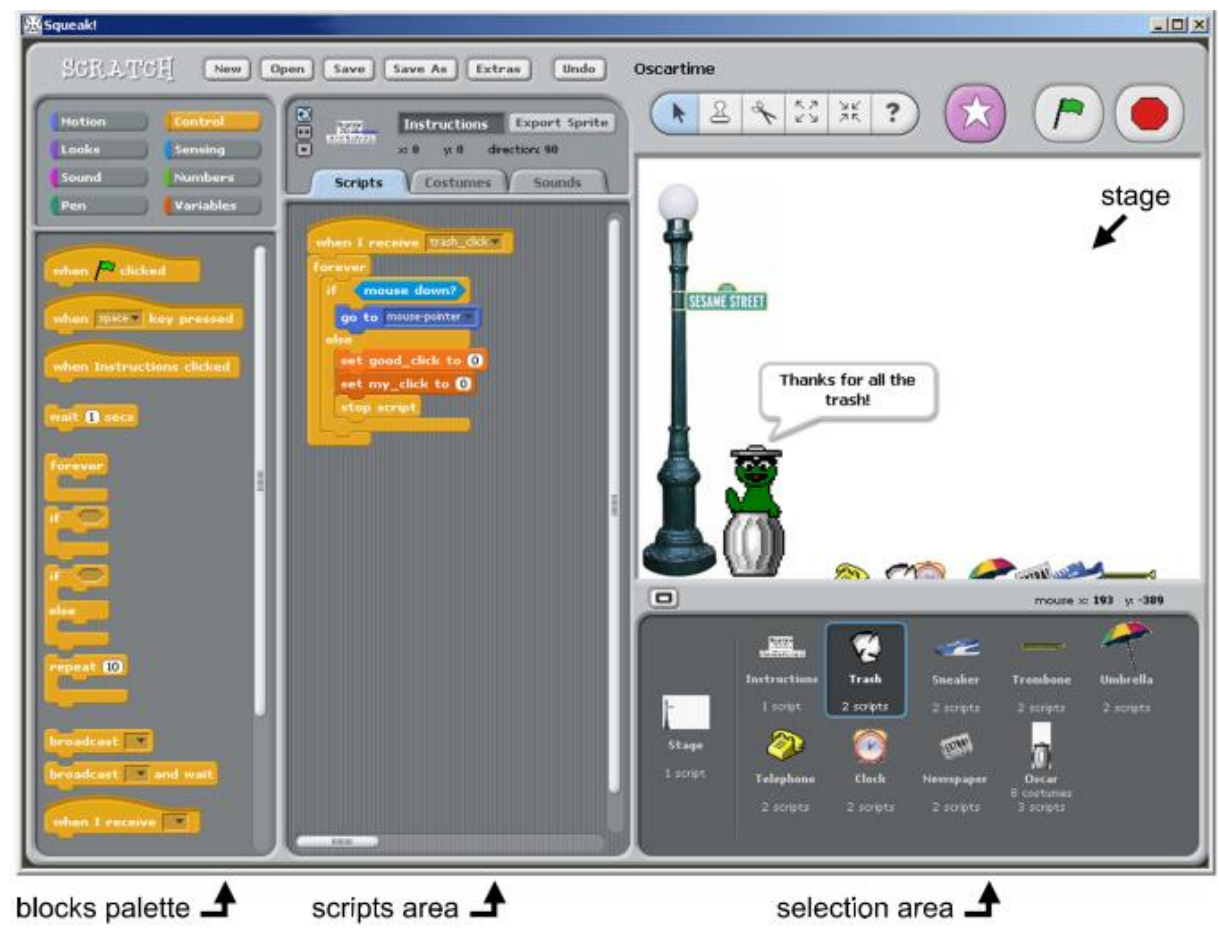

Figura 1: Interface de Desenvolvimento da Ferramenta Scratch

${ }^{1}$ http://www.codemonkey.co.il/ 
O desenvolvimento de projetos na ferramenta é fácil, pois fornece um ambiente que possibilita a construção de projetos como se fossem histórias animadas, apresentações interativas ou jogos. Além disso, o Scratch inclui construções de repetição, condicionais, comunicações, sons, e variáveis, o que permite introdução de conceitos que muitas vezes são difíceis para os alunos das séries iniciais do curso de ciência da computação entenderem são vistos na ferramenta de uma forma descontraída, pois estão implícitos na mesma.

Scratch tem sido utilizado como um auxílio para o aprendizado de Java em um curso introdutório de ciência da computação na Universidade de Harvard [Malan, 2007], e também pode ser utilizado da mesma maneira em escolas de ensino fundamental gerarando um interesse precoce em ciência da computação [Malcom et.al., 2008].

Scratch é diferente de ambientes mais tradicionais usados para introduzir idéias de ciência da computação, pois seu ambiente de programação de "arrastar-e-soltar" incentiva a experimentação, elimina problemas de sintaxe, e permite que os alunos se concentrem na resolução de problemas e no design do algoritmo. Sua ênfase em gráficos, animação, som e interação com o usuário permite que os alunos trabalhem em problemas que envolvam o seu interesse [Margolis et.al., 2002].

\section{Resultados e discussão: proposta de aplicação de Scratch para alunos do ensino médio}

A proposta deste trabalho consiste na execução de uma sequencia de etapas descritas a seguir. As atividades se iniciam com oficinas de lógica de programação por meio da ferramenta Scratch para um grupo pequeno e selecionado de alunos e professores envolvidos no projeto. Essas oficinas ocorrem na Universidade de forma gradual, onde os alunos desenvolvem os conhecimentos de lógica de programação de forma lúdica e criativa. Assim, os alunos implementam desafios a partir de condicionais primitivos, como por exemplo os condicionais "se", "enquanto", desenvolvendo suas habilidades, sem a necessidade dos primitivos de sintaxe exigidos em linguagens como Java e C. Dessa forma, eles se preocupam com o desenvolvimento da lógica do jogo em si, sem preocupações com detalhes de implementação (problemas inerentes a programação, como por exemplo, falta de parênteses ou chaves).

Após a preparação desse conjunto de alunos e professores, as oficinas são aplicadas na escola pública envolvida, onde os alunos preparados atuam como monitores. Essas oficinas na escola tem duração de 24 horas/aula, realizadas junto ao laboratório de informática de ensino médio em questão com a frequência de duas vezes na semana. Os alunos atendidos pelas oficinas serão dos últimos dois anos do ensino médio. Essas oficinas são aplicadas nas disciplinas de matemática e física e envolvem problemas a serem resolvidos relacionados ao conteúdo visto em aula, despertando nos alunos o interesse pela solução de problemas de forma não tradicional, e sim por meio de jogos e programas desenvolvidos no Scratch.

Questionários antes e depois da realização dos cursos são aplicados, com o intuito de identificar possíveis mudanças de postura, da parte dos alunos, com relação à resistência quanto à lógica de programação, uma vez que esse conteúdo os alunos julgam ser complicado e difícil. Também é avaliado nos alunos o interesse por ciências exatas e da Terra antes e após as oficinas de Scratch. 


\section{Considerações Finais}

Até o momento o projeto encontra-se na fase de término do treinamento do grupo de alunos selecionado e professores e preparação do laboratório de informática na escola para a aplicação das oficinas. O grupo de 8 alunos que já realizou a oficina demonstrou muito interesse em continuar o estudo de lógica de programação e da ferramenta Scratch. Esses alunos tem desenvolvido jogos para a solução de problemas de matemática antes resolvidos de formas tradicionais.

A próxima etapa envolve a aplicação da oficina na escola, com uma turma maior de alunos. A análise que pretendemos fazer é qualitativa e quantitativa, baseada em questionário com questões abertas e fechadas.

\section{Referências}

Malan, David J. and Leitner, Henry H., "Scratch for Budding Computer Scientists", in Proc. of the 38th SIGCSE Technical Symposium on Computer Science Education, pp. 223-227, Covington, KY, 2007.

Malcom, S., Teich, A.H., Jesse, J.K., Campbell, L.A., Babco, E.L., and Bell, N.E. Preparing Women and Minorities for the IT Workforce: The Role of Nontraditional Educational Pathways. Report by AAAS Education and Human Resources Programs, AAAS Science \& Policy Programs, and the Commission on Professionals in Science and Technology. 2005.

Maloney, J. H., Peppler, K., Kafai, Y., Resnick, M., \& Rusk, N. (2008, March). Programming by choice: urban youth learning programming with scratch. In ACM SIGCSE Bulletin (Vol. 40, No. 1, pp. 367-371). ACM.

Margolis, J. and Fisher, A. Unlocking the Clubhouse: Women in Computing. MIT Press. 2002.

McCray, R. A., R. L. DeHann \& J.A. Schuck (2003), Editors, Improving Undergraduate Instruction in Science, Technology, Engineering, and Mathematics: Report of a Workshop, Editors, The National Academies Press, Washington DC.

Resnick, M., Kafai, Y., and Maeda, J. 2003. ITR: A Networked, Media-Rich Programming Environment to Enhance Technological Fluency at After-School Centers in Economically Disadvantaged Communities. Proposal [funded] Washington, DC: National Science Foundation.

Resnick, M., Rusk, N., and Cooke, S. 1998. Computer Clubhouse: Technological fluency in the inner city. D. Schon, B. Sanyal and W. Mitchell (Eds.), High technology and low-income communities. Cambridge, MA: MIT Press.

Sousa, j. M. de (2011). A Inserção de Softwares Educativos pelo Corpo Docente dos Anos Iniciais do Ensino Fundamental: Velhos Problemas e Novos Desafios. Monografia. Universidade Federal do Piauí Campus Senador Helvidio Nunes de Barros Curso de Licenciatura Plena em Pedagogia.

Valente, José; Freire, Fernanda M. P.; Rocha, Heloísa V.; D’a Breu, João V.; Baranauskas, Maria C. C.; Martins, Maria C.; Prado, Maria E. B. B. (1998). O computador na sociedade do conhecimento, coleção informática para a mudança na educação.

Valente, José A.(1998). Informática na Educação no Brasil Análise e Contextualização Histórica.

Wolz, U., Maloney, J., \& Pulimood, S. M. (2008, March). 'scratch'your way to introductory cs. In ACM SIGCSE Bulletin (Vol. 40, No. 1, pp. 298-299). ACM. 